\title{
Processo de ascenção ao cargo e as facilidades e dificuldades no gerenciamento do território na Estratégia Saúde da Família*
}

\author{
Process of ascenssion to position and the ease and \\ difficulties in the management of territory in the Family Health Strategy \\ Proceso de asensión al cargo y las facilidades y dificuldades \\ en la gerencia de territorio en la Estrategia Salud de la Familia
}

\author{
Francisco Rosemiro Guimarães Ximenes Neto', José Jackson Coelho Sampaio" \\ 'Universidade Estadual do Vale do Acaraú, Sobral, CE \\ "Universidade Estadual do Ceará, Centro de Ciências da Saúde, Fortaleza, CE
}

Submissão: 02/08/2007

Aprovação: 12/12/2007

\begin{abstract}
RESUMO
O estudo objetiva caracterizar o processo pelos quais os gerentes de território da Estratégia Saúde da Família-ESF ascenderam ao cargo e os limites e/ou facilidades encontradas por este em seu processo de trabalho. A pesquisa é de abordagem predominantemente Qualitativa, realizada em Sobral-Ceará, com 28 gerentes de território da ESF, no período de novembro de 2006 a junho de 2007. O processo Que levou os gerentes ao cargo, não leva em consideração um perfil de competências, ocorrendo de maneira administrativamente artesanal. As principais facilidades no processo de trabalho dos gerentes se dão principalmente, pelo bom relacionamento com a equipe e o compromisso desta. lá as dificuldades referem-se a conciliação das atividades de enfermagem e gerenciamento e falta de capacitação para o gerenciamento.
\end{abstract}

Descritores: Programa Saúde da Família; Gerenciamento; Enfermagem.

\section{ABSTRACT}

The study aims to characterize the process by which the territory managers of the Health Strategy of the Family- HSF ascended to the position and the limits and/or ease found by them in their work process. The research is of a predominantly qualitative approach, accomplished in Sobral-Ceará, with 28 territory managers of the HSF, in the period of November of 2006 to lune of 2007. The process that took the managers to the position, does not take into consideration a profile of competences, occurring in a handmade administrative way. The main ease in the managers' process work mainly happens, due to the good relationship with the team and its commitment. Yet the difficulties refer the conciliation of the nurse activities and management and lack of training for management.

Descriptors: Family Health Program; Management; Nursing.

\section{RESUMEN}

El estudio tiene como objetivo caracterizar el proceso por el cuál los gerentes de territorio de la Estrategia Salud de la Familia ESF ascendieron al cargo y los limites e/o dificultades encontrados por estos en su proceso de trabajo. La pesquisa es de abordaje predominantemente cualitativo, realizada en Sobral Ceará, con 28 gerentes de territorio de la ESF, en el periodo de Noviembre de 2006 a Junio de 2007. El proceso Que llevó a los gerentes al cargo, no lleva en consideración un perfil de competencias, ocurriendo de manera administrativamente artesanal. Las principales facilidades en el proceso de trabajo de los gerentes se dan por la buena relación con el equipo y el compromiso de este. Ya las dificultades se refieren a la conciliación de las actividades de enfermería, gerencia y falta de capacitación para la gerencia.

Descritores: Programa Salud de la Familia; Gerencia; Enfermería.

*Dados extraídos da dissertação de Mestrado intitulada "Gerenciamento no Território da Estratégia Saúde da Família: análise do processo de trabalho dos gerentes" do Programa de Pós-Graduação em Saúde Pública, da Universidade Estadual do Ceará-UECE/Fortaleza, defendida em junho de 2007.

Correspondência: Francisco Rosemiro Guimarães Ximenes Neto. Av. da Universidade, 850. Campus da Betânia. CEP - 62040-370. Sobral, CE. 


\section{INTRODUÇÃO}

O Programa de Saúde da Família (PSF) surgiu em 1994 como uma grandiosa proposta de incremento da descentralização do Sistema Único de Saúde-SUS e efetivação da Atenção Primária à Saúde-APS no Brasil. O PSF em sua criação teve como objetivo desenvolver ações de promoção e proteção à saúde do sujeito, de sua família e comunidade, mediante atendimento por equipes de saúde no nível de APS ${ }^{(1)}$.

Com o avançar do PSF, tanto nos aspectos Quantitativos - elevado número de municípios com o programa implantado e o aumento do número de equipes, assumindo abrangência nacional - como Qualitativos - melhoria dos indicadores de morbidade e mortalidade e, conseQüente, melhoria da Qualidade de vida das famílias, sujeitos e comunidades -, o mesmo deixar de ser um programa governamental, passando a uma política estratégica de APS. Pois, segundo o próprio MS, o PSF apresentava condições de resolver efetivamente mais de $85 \%$ dos problemas de saúde da população atendida ${ }^{(2)}$. Nesse sentido, em 1997, o MS em publicação admite ser o PSF uma estratégia, por sua abrangência, seu impacto e resolubilidade, além de buscar a "[...] reversão do modelo assistencial vigente. Por isso, [...] sua compreensão só é possível através da mudança do objeto de atenção, forma de atuação e organização geral dos serviços, reorganizando a prática assistencial em novas bases e critérios"(3).

De acordo com Antunes e Egry ${ }^{(4)}$ a ESF é a "principal estratégia para solucionar os males da saúde pública seja no universo políticopartidário, das corporações profissionais da saúde, no setor de formação em saúde e na própria sociedade".

O processo de organização da ESF exige a definição de um território, com população adscrita, unidade de saúde de referência e a constituição de uma eQuipe mínima composta pelo menos por um enfermeiro, médico, auxiliar de enfermagem, agentes comunitários de saúde com coordenação da Secretaria Municipal da Saúde.

Na prática organizativa da equipe da ESF no território, tem sido cada vez mais premente, a inclusão de um trabalhador gerente, Que gerencie este, devido processo organização do trabalho, Que passa por um novo padrão de Qualidade, como conseqüência das transformações oriundas de experiências de integração, tanto por suas "implicações organizacionais, em relação à necessidade de interrelação entre diferentes serviços, como em relação às modificações introduzidas no conteúdo técnicos do trabalho". Sendo que, essas alterações vêm dar respostas às "necessidades originadas no interior do processo de trabalho Que, ao modificar-se, 'exigem' novos modelos gerenciais Que possam instrumentalizar sua operação"(5).

Ao levarmos em consideração Que a prática do gerenciamento de território na ESF é algo novo, recente, não sendo ainda uma definição administrativa em sua totalidade para as equipes, mesmo sendo uma política emanada com a NOB - SUS 01/1996, gerenciar território, necessita de profissionais Que tenham a sensibilidade de compreender os processos sociais, políticos, culturais, epidemiológicos, ecológicos, enfim os históricos. Além do mais, a prática de gerenciamento deverá agregar saberes e práticas próprias das Ciências Sociais, da Saúde e Humanas. Gerenciar coletivamente é outra prerrogativa para tais gerentes. Segundo Campos $^{(6)}$, a implantação de um novo modelo de saúde é praticamente impossível efetivá-lo "sem que a maioria dos gerentes e dos trabalhadores de saúde não só estejam de acordo com a nova proposta como também se empenhem em consolidá-la".

Vanderlei ${ }^{(5)}$ afirma Que para a construção do SUS, e conseeüente descentralização dos serviços de saúde, a gestão e a gerência entra na pauta das discussões, como prioridade da agenda política, "[...] tendo em vista Que para consolidação desse sistema único é necessária uma outra lógica, isto é, uma outra organização dos serviços de saúde Que implique na articulação entre o modelo de gestão e o modelo da atenção".

A Questão da gerência dos serviços de saúde, conforme Campos ${ }^{(7)}$ exige uma urgência de ser repensada criticamente. Nesse sentido, o presente estudo objetiva caracterizar o processo pelo Quais os gerentes de território da ESF ascenderam ao cargo e os limites e/ ou facilidades encontradas por este em seu processo de trabalho.

\section{MÉTODO}

A pesquisa é de abordagem predominantemente Qualitativa. $\mathrm{O}$ estudo foi realizado em Sobral - Ceará, no período de novembro de 2006 a junho de 2007. Os sujeitos desta pesquisa foram constituídos por 28 gerentes de território na ESF, estando os mesmos, assim distribuídos geograficamente 14 na zona urbana e igual número na zona rural.

Para a coleta de dados referente as facilidades e dificuldades encontradas no gerenciamento do território foi utilizado como instrumento, um Questionário. Os dados acerca do processo pelos Quais os gerentes ascenderam aos cargos foram coletados a partir de uma entrevista semi-estruturada. Os Questionários foram aplicados, durante a roda de gestão dos gerentes com a Coordenação Municipal da APS. Antes da aplicação do Questionário foi realizado um pré-teste, com três gerentes, para validação do mesmo. No momento da coleta dos dados, por meio dos Questionários, estavam ausentes 11 gerentes, sendo Que o referido instrumento foi entregue aos seus representantes na roda, para Que os mesmos preenchessem e enviassem à Escola de Saúde da Família Visconde de Sabóia-EFSFVS. Foi orientado que os Questionários fossem enviados em envelope lacrado, para manter o sigilo das informações.

As entrevistas foram realizadas por meio do agendamento prévio, com hora marcada, nos Centros de Saúde da Família-CSF, como também nos espaços da EFSFVS, de modo Que preservasse a privacidade dos gerentes. As cinco primeiras entrevistas foram gravadas, com o consentimento dos sujeitos. Porém, nove dos entrevistados não aceitaram a gravação das entrevistas; por conta disso, optamos por não gravar as demais, por perceber Que estes estavam ficando inibidos. Os dados das entrevistas estão analisados a partir do processo de categorização proposto por Minayo ${ }^{(8)}$ e os referentes às facilidades e dificuldades no gerenciamento foram categorizados por aproximação em tabelas.

Após os devidos esclarecimentos, os sujeitos assinaram o Termo de Consentimento Livre e Esclarecido. Para a realização do estudo foi buscada, inicialmente, a permissão da Secretaria da Saúde e Ação Social do Município de Sobral-CE, por meio do Núcleo de Estudos e Pesquisas em Saúde-NEPS, Quando foi encaminhado o protocolo de pesquisa, sendo este analisado e, em seguida, deliberado em favor desta; por conseguinte, o referido protocolo foi encaminhado ao Comitê de Ética e Pesquisa da Universidade 
Estadual do Ceará-UECE, sendo o mesmo aprovado. Para preservação dos sujeitos da pesQuisa, o nome destes foi substituído por nomes marianos, no caso das mulheres, e o dos homens, por nomes bíblicos.

\section{RESULTADOS E DISCUSSÃO}

\section{Processo Que Levou o Enfermeiro ao Cargo de Gerente}

As falas extraídas a partir das entrevistas com os gerentes mostram Que a gerência do território da ESF está centrada no enfermeiro, e Que não há um processo estruturado para ascensão dos profissionais ao cargo de gerente. As falas estão apresentadas a partir das seguintes subcategorias: Gerente Líder, Gerente Organizadora, Gerente Quem Indica-QI e Gerente EnfermeiroCentrado.

\section{Gerente Líder}

Eu era enfermeira de Saúde da Família, de uma área. Fui avaliada, e chamada pela Secretaria da Saúde, pela Coordenação de Saúde, Que chegou pra mim, e falou que eu tinha um perfil de líder, e que poderia está atuando muito melhor, em outro território como gerente (Maria dos Remédios).

Foi percebido pelo gestor Que no meio de um grupo eu me destacava, como aquela pessoa Que podia exercer o cargo de gerente (Maria da Consolação).

Foi realizada eleição na roda. Eu ganhei com mais de 80\% dos votos (Maria do Rosário).

As falas indicam Que o trabalho desenvolvido pelas enfermeiras permitiu o despontar da liderança no território da ESF. O trabalho foi percebido e valorizado pela própria ęuipe e pela coordenação geral da ESF, resultando na ascensão ao cargo de gerente.

O trabalho exercido na ESF, exige da equipe, principalmente da gerência, o exercício pleno de uma liderança competente, para Que a mesma possa mobilizar processos, vontades e estratégias organizacionais, com o intuito de ampliar os espaços de influência do trabalho em saúde, alcançar as metas estabelecidas pela gestão sanitária municipal, cumprir o Que está previsto no Plano Municipal de Saúde, na Lei № 8.080/1990 e buscar a efetivação dos princípios do SUS, principalmente da integralidade.

A liderança deve ser uma das características fundamentais do gerente, para o competente exercício da função. A liderança na ESF deve ser carismática, executiva, resolutiva, empreendedora, acolhedora, para Que possa propiciar a construção de vínculos, mobilizar vontades, e mediar democraticamente os conflitos internos da equipe-equipe, entre equipe e comunidade e internas da comunidade. A liderança deve, ainda, apresentar maturidade em situações de crise, como nos casos de epidemia, de catástrofe ou de conflitos político-sociais intensos. Deve pregar a afetividade entre equipe-comunidade, alimentar sonhos, inspirar o futuro, e juntos buscarem a resolução dos problemas e necessidades sanitárias, construindo uma cultura de solidariedade, baseada no bem comum e no amor coletivo.

A liderança, de acordo com Shinyashiki(9) "é a arte de inspirar as pessoas em direção aos objetivos delas [...]. É a arte de criar felicidade para os outros. Uma das maneiras mais ricas de experimentar a felicidade é a possibilidade de pôr em prática um sonho". O verdadeiro líder segundo o autor deve promover a autonomia $\mathrm{e}$ cooperação de sua eQuipe. Esse espírito de liderança carismática, segundo Weber ${ }^{(10)}$, surgiu em todos os lugares e vem se desenvolvendo em todas as épocas históricas.

No caso do enfermeiro-líder, gerente de território da APS, Alves $^{(11)}$ a partir de idealizações de Vergara, apresenta algumas capacidades necessárias: "Ter clareza euanto aos objetivos e estratégias para o desenvolvimento dos programas na UBS. [...] Monitorar as necessidades e expectativas da comunidade e da equipe de saúde. [...] Ter habilidade para solucionar problemas. [...] Ser criativo. [...] Fazer da informação uma das ferramentas de trabalho. [...] Ter iniciativa e comprometimento com seu trabalho e com a comunidade. [...] Ouvir e ser ouvido [...] Reconhecer o potencial existente nos outros. [...] Viabilizar a comunicação. [...] Pensar globalmente e agir localmente. [...] Conhecer o trabalho realizado pelos demais integrantes da equipe".

A liderança no gerenciamento do território da ESF pode ser transformadora, estratégica, democrática, liberal ou autocrática, o Que irá caracterizá-la será o processo político do momento ou a cultura organizacional em Que o gerente esteja inserido. Mas é importante assegurarmos Que o modelo de liderança democrática, com base na gestão participativa, é o mais apropriado para a ESF. No nosso entendimento, o gerente deve apresentar-se como um líder com várias capacidades:

a) a de atuar como potencializador de uma aprendizagem coletiva em busca de um bem comum; motivador de vontades para construção de um mundo mais justo e eQuânime; agente político junto aos poderes locais, com o intuito de buscar a transformação da realidade local, para melhoria dos níveis de saúde da comunidade e potencialização do território, como espaço de poder e de desenvolvimento laboral e renda para a comunidade.

b) a de possuir as competências do conhecimento acerca do território, do planejamento, da epidemiologia, da gestão participativa, da ESF onde esteja inserido e do SUS, apresentando visão de futuro e respeito à subjetividade e motivador, comunicador, mobilizador, educador, negociador, organizador, com criatividade e ética.

c) a de colocar na agenda de seu trabalho diário os princípios norteadores da Política Nacional de Humanização.

O líder na APS, de acordo Alves ${ }^{(11)}$ trabalha buscando o crescimento e desenvolvimento humano coletivo - seu de gerente e dos trabalhadores de saúde -, com o intuito de melhorar os indicadores de saúde do território em Que atua.

O gerente líder, com sua equipe e a comunidade deve buscar criar o futuro de seu território, com vistas à melhoria dos indicadores de morbidade e mortalidade e da eualidade de vida das famílias, com base na promoção da saúde e na cidadania integral.

\section{Gerente Organizadora}

Foi um convite, [...] por Que eu não concordava com o modelo de atendimento por fila e tinha feito uma discussão com a eQuipe (Maria dos Impossíveis).

Eu estava trabalhando [...]. Estava insatisfeita, pedir para sair. Tinham algumas coisas Que eu não concordava. Então fui convidada a está assumindo a gerência de outra unidade (Maria do Perpetuo Socorro). 
Fui chamada pela Coordenação [...], Que durante o meu processo de assistência, ela percebia Que eu era uma pessoa Que procurava trabalhar com certo nível de organização... (Maria dos Navegantes).

O fato de o profissional de saúde, no caso a enfermeira, estar trabalhando na base, mas ineuieto, incomodado com a cultura organizacional empregada pela gerência no processo de trabalho da equipe de seu território, ou sempre estar buscando trabalhar com competência e Qualidade, foram os motivos ímpares para sua ascensão funcional ao cargo de gerente.

Numa corporação competente, o simples fato de um dos membros da eQuipe não concordar com sua cultura organizacional ou estar insatisfeito com esta, não é o motivo suficiente para ser agraciado com ascensão a um cargo. Tal situação deveria depender da construção social vivenciada na organização, e a partir de critérios técnicos e tecnológicos é Que ocorreria a substituição gerencial. Não basta ineuietação, pode ser apenas competição.

O gerente, gestor ou administrador, a depender de seu modelo gerencial, construído socialmente, pode influenciar na cultura organizacional a ponto de mobilizar os diferentes agente - equipe e clientela -, a construir consigo uma prática satisfatória para efetivação dos objetivos de ambos. Existem gerentes autocráticos Que conseguem levar a equipe a efetivar objetivos gerenciais pessoais, com o intuito de empregar uma cultura organizacional sua, Que venha atender às próprias vontades. Esta prática gerencial pode levar e leva parte da equipe ao incômodo, à inQuietação, à rebeldia, podendo resultar em luta interna ou acomodação pela passividade, pela fuga da luta.

\section{Gerente Quem Indica-QI}

Quando vim a Sobral, substituí uma gerente e depois assumir a gerência de outra unidade [...]. Dizem que é o QI-Quem indica (Maria do Bom Conselho).

Foi por indicação da gerente anterior, por eu já estar envolvida com o processo de trabalho dela, a gente trabalhava em conjunto [...] (Maria do Bom Parto).

A indicação por terceiros foi a forma Que as gerentes Maria do Bom Conselho e Maria do Bom Parto ascenderam ao cargo. O processo de gerenciamento da ESF no município de Sobral está pautado na gestão participativa, com rodas, base na gestão de coletivos. Assim, tais formas de ascensão de gerentes já não deveriam existir. A base da ascensão deveria ser a competência política, humana e técnica, Que possibilitaria aos membros da roda realizarem avaliação prévia e tomarem decisão consensual, e Que esse gerente fosse um profissional de carreira municipal, fato impossível atualmente, pois nenhum é concursado.

\section{Gerente Enfermeiro-Centrado}

[... o que levou a Secretaria a lembrar do meu nome, foi a minha experiência como enfermeiro e a indicação da equipe (Jesus).

O médico não Queria ser gerente. A enfermeira Que era, tinha saído. Tinha Que ser eu. Nunca me achei com o perfil de gerente (Maria Auxiliadora).

Nós éramos duas [enfermeiras], se bem Que tem outros profissionais de nível superior, mas a gerência está tão centrada na enfermeira, Que nem se cogitou a possibilidade do dentista, porQue de cara já não tem uma empatia por isso [...]. Eu assumir por Que a outra colega saiu para licença a maternidade (Maria Aparecida).

[... Foi por livre e espontânea pressão mesmo. Por medo de perder o cargo. Pois só tinha eu na unidade que poderia ser, as outras enfermeiras não Queriam de maneira alguma [...]. Tinha medo de ficar marcada, perder o cargo (Maria de Lourdes).

Em Sobral, tem sido comum nos últimos anos a gerência dos territórios da ESF estar centrada no profissional enfermeiro. Tal fato acreditamos Que deve-se a três situações:

a) Nem sempre os profissionais de outras categorias aceitam a gerência, principalmente os médicos, pela sobrecarga de trabalho Que a mesma exige, o excesso de burocracia, e em muitos dos casos ainda ter Que atuar na atenção;

b) $\mathrm{O}$ valor pago pela gratificação é irrisório para a carga de trabalho e a responsabilidade assumida;

c) Durante algum tempo, por conta do modelo de gestão participativa, era prática nos territórios da ESF as próprias equipes escolherem seus gerentes por meio de eleição direta, durante as Rodas dos Territórios. Como os enfermeiros, em seu processo de trabalho buscam a gestão do cuidado na perspectiva holística, envolvendo outros profissionais e as famílias, sem deixar de referenciar, estão mais presentes e demonstram maior apoderamento do território e da cultura organizacional do CSF, isto os coloca em situação decisiva para assumir a gerência.

Como membro da equipe de saúde, o enfermeiro, segundo Cunha e Ximenes Neto $^{(12)}$, é responsável por inúmeras atividades, tais como aquelas relacionadas ao cuidado direto ao cliente, a liderança da equipe de enfermagem e o gerenciamento de pessoal e de recursos físicos, materiais, financeiros, políticos e de informação, durante a prestação da assistência de enfermagem. Para autor ${ }^{(1)}$, o perfil gerencial do enfermeiro na APS é definido a partir de um conjunto de aptidões, habilidades e atitudes, e que tal perfil deva compreender alguns elementos tais como, conhecimento técnico-científico a ser utilizado na avaliação e, identificação das necessidades de saúde dos sujeitos e de sua comunidade, além da ética, motivação, comunicação, capacidade de gerenciar conflitos e liderança.

Entretanto, o enfermeiro-líder "deve conhecer os processos sociais, culturais, comportamentais dos sujeitos, bem como as formas como as instituições de saúde estão organizadas $[. . .]^{(11) "}$. Afirma ainda, a necessidade de ser ético, o que "[...] significa resgatar valores humanos como respeito, humildade. Dedicação e dignidade, tão importantes para desenvolver o trabalho gerencial com Qualidade".

O enfermeiro pode assumir, naturalmente, a gerência de uma UBS ou CSF ou Unidade de Saúde da Família-USF, independente da denominação, este fato vem acontecendo com certa freqüência, desde os anos 1980. Porém, mesmo Quando isso não acontece, 
ele tem a responsabilidade pela coordenação da equipe de enfermagem ${ }^{(13)}$.

\section{Facilidades e Dificuldades no Gerenciamento do Território}

O trabalho na ESF deve estar organizado de modo Que as facilidades permeiem todas sua as fases de construção, da seleção da equipe multiprofissional à consecução dos resultados, passando por planejamento, organização e processo trabalho. O gestor municipal da saúde, nessa situação, deve estar apto e aberto a construir um modelo organizacional e de atenção à saúde Que consiga valorizar as tecnologias existentes no território e as Que por ventura venham a surgir, principalmente aquelas relacionadas à gestão de pessoas.

Entre os 28 gerentes, 20 apontaram como facilidades relacionadas ao trabalho de equipe, o relacionamento, o compromisso e a formação continuada, assim facilitando o trabalho dos gerentes no território (Tabela I). Os gerentes, ao apontarem os trabalhadores de saúde como elemento estratégico ao gerenciamento do território, estão respaldando os investimentos Que Sobral vem realizando em sua ESF, desde a educação permanente, como ao estímulo à gestão participativa e ao desenvolvimento de lideranças nos territórios, apesar a precarização do trabalho dos trabalhadores.

Quanto a essa visão de trabalhadores colaboradores, para Que isto ocorra, Gómez-Mejía, Balkin e Cardy ${ }^{(14)}$ apontam como novas necessidades para o gerenciamento de pessoal: "uma nova visão do homem, do trabalho e da empresa. Estrutura plana, horizontalizada, enxuta, de pouco níveis hierárQuicos. Organização voltada para processos e não funções especializadas e isoladas. Necessidade de atender ao usuário - interno ou externo - e, se possível, encantá-lo. Sintonia com o ritmo e a natureza das mudanças ambientais. Visão voltada para o futuro e para o destino da empresa e das pessoas. Necessidade de criar valor e de agregar valor às pessoas, às empresas e ao cliente. Criação de condições para uma administração participativa e baseada em equipes. Agilidade, flexibilidade, dinamismo e proação. Compromisso com a Qualidade e com a excelência de serviços. Busca da inovação e da criatividade".

Acreditamos Que o pessoal de uma organização é seu maior patrimônio, devendo o mesmo ser valorizado e priorizado nos investimentos e no financiamento sanitário.

A organização do serviço de saúde foi apontada, por seis gerentes, como um aspecto facilitador do trabalho. Historicamente, tem sido percebido no setor saúde, Que um serviço com um nível razoável de organização, ou seja, com um planejamento realizado com base nas necessidades locais, pessoal com papéis e atribuições definidas e executados com Qualidade, provimento de equipamentos e insumos necessários, demanda organizada e uma atenção humanizada tem levado a bons resultados, a exemplo da melhoria dos indicadores de mortalidade e morbidade, como também da satisfação da clientela e conseQüente melhoria da Qualidade de vida desta.

O conhecimento das características do território foi apontado por três gerentes como imprescindível. Na perspectiva da organização da atenção na ESF, o conhecimento, compreensivo e crítico, do território, com suas diversidades físicas e políticas e as subjetividades dos sujeitos e da coletividade, ajuda na compressão dos processos sócio-sanitários, além dos históricos, constitui condição sine Qua non para a construção de um plano de cuidado mais próximo à realidade, aumentando as possibilidades de sua efetivação.

Segundo a gerente Maria Aparecida, o reconhecimento do território, a partir da territorialização tem

[...] o objetivo de estar delimitando áreas risco, para eu ter uma visão melhor de Qual população alvo que eu vou trabalhar, [...] para [...] ajudar a planejar as estratégias e a forma de trabalho. [...] A territorialização permite você perceber dados Que a tua visão não alcança tipo: delimitar área de risco, Quantificar o real do número de famílias. Com a territorialização esses dados ficam mais real, você trabalha em cima de uma coisa mais concreta [...].

O conhecimento do território, a partir da territorialização, conforme apresentado pela gerente Maria Aparecida, permite uma melhor organização do processo de trabalho e da atenção na ESF. Três gerentes apontaram o apoio dado pela Secretaria de Saúde, como um aspecto facilitador de seu trabalho. Por outro lado, Quatro dos gerentes referiram como aspecto dificultador a falta de apoio da Secretaria de Saúde, o Que confirma a importância deste relacionamento no sucesso ou fracasso do trabalho.

A Roda de Gerentes e a Roda dos Territórios foram apontadas por três gerentes como dispositivo necessário à boa gestão. A prática de uma gestão participativa nos territórios da ESF, com o coletivo de gerência, contribui significativamente para o processo de produção social em saúde, e responsabiliza todos os trabalhadores de saúde, colocando-os numa posição de co-gestores.

As Rodas dos Territórios, segundo autora ${ }^{(15)}$, "surge como um espaço de discussão coletiva advinda do trabalho em equipe, para Que as construções, as decisões e os planejamentos sejam compartilhados coletivamente, sendo este um exercício da democracia”.

A educação permanente foi referida, por dois gerentes, como algo importante para o gerenciamento. $\mathrm{O}$ investimento com os trabalhadores de saúde em Sobral, no Que concerne à Qualificação, tem sido um dos fatores atrativos e de manutenção dos mesmos no Sistema Municipal, mesmo com a inexistência de um Plano de Carreiras, Cargos e Salários-PCCS e a realização de concurso público somente para os profissionais médicos.

Dez dos gerentes apontaram como dificuldade em gerenciar o território a conciliação do processo de trabalho de enfermeiro com o de gerente, conforme as falas a seguir:

[...] umas das dificuldades da gente que é gerente e tem um território sob a nossa responsabilidade é assim, porque nós também temos um cronograma de atendimento [...], então muitas vezes a gente tem Que planejar muito bem as ações Que vai fazer, para ter aquele tempo específico para gerência [...]. Muitas vezes a gente tem Que ficar entre um intervalo, entre um atendimento e outro pra resolver problemas de gerência. Então é assim, fica muito corrido nesse sentido. Atender telefone e fazer as ligações necessárias. Atender as colegas Que chegam com demanda tem que ser resolvida na hora, então é complicado, nesse sentido (Maria das Graças).

Num sistema de saúde como o de Sobral, em Que a ESF apresenta 
Tabela I Facilidades encontradas no trabalho como gerente do território da Estratégia Saúde da Família. Sobral CE, 2006.

\begin{tabular}{|c|c|c|}
\hline FATORES FACILITADORES & $\mathrm{n}$ & $\%$ \\
\hline Bom relacionamento com a equipe & 11 & 39,3 \\
\hline A organização do serviço de saúde [...] & 6 & 21,4 \\
\hline Equipe compromissada com o trabalho & 5 & 17,9 \\
\hline EQuipe multiprofissional & 4 & 14,3 \\
\hline Apoio dado pela secretaria & 3 & 10,7 \\
\hline Conhecimento das características do território & 3 & 10,7 \\
\hline Roda de gerentes e da equipe de saúde & 3 & 10,7 \\
\hline Educação permanente & 2 & 7,1 \\
\hline O apoio de outras secretarias & 2 & 7,1 \\
\hline EQuipe de enfermagem & 2 & 7,1 \\
\hline Interação com as redes sociais & 2 & 7,1 \\
\hline Disponibilidade de carro para equipe [...] & 2 & 7,1 \\
\hline Avaliação e observação dos problemas & 1 & 3,6 \\
\hline [...] o tempo na gerência & 1 & 3,6 \\
\hline Boas condições de trabalho na UBS & 1 & 3,6 \\
\hline Não está responsável por áreas & 1 & 3,6 \\
\hline Liderança como característica pessoal & 1 & 3,6 \\
\hline Gostar de gerenciar o serviço & 1 & 3,6 \\
\hline Apoio de [...] residentes - núcleo- em algumas situações & I & 3,6 \\
\hline Organização da demanda & I & 3,6 \\
\hline O trabalho dos ACS com a comunidade & 1 & 3,6 \\
\hline Disponibilidade de medicamento [...] & I & 3,6 \\
\hline Co-gestão participativa & 1 & 3,6 \\
\hline Aula sobre organização de serviço & I & 3,6 \\
\hline Tempo de moradia e atuação no território & I & 3,6 \\
\hline Conhecimento da comunidade & 1 & 3,6 \\
\hline Não respondeu & 2 & 7,1 \\
\hline
\end{tabular}

Tabela 2 Dificuldades encontradas no trabalho como gerente do território da Estratégia Saúde da Família. Sobral - CE, 2006.

\begin{tabular}{|c|c|c|}
\hline FATORES DIFICULTADORES & $\mathrm{n}$ & $\%$ \\
\hline Conciliar atividade de enfermagem e gerenciamento & 10 & 35,7 \\
\hline Estrutura física da unidade & 9 & 32,1 \\
\hline Falta de capacitação para o gerenciamento & 6 & 21,4 \\
\hline A politicagem por parte dos cabos eleitorais & 6 & 21,4 \\
\hline Pouca autonomia & 5 & 17,9 \\
\hline Excesso de burocracia & 5 & 17,9 \\
\hline Falta de compromisso de alguns membros da equipe & 4 & 14,3 \\
\hline Falta de autonomia com os profissionais Que não têm perfil para o trabalho & 4 & 14,3 \\
\hline Comunicação com os outros setores da Secretaria da Saúde & 4 & 14,3 \\
\hline Falta de apoio da Secretaria da Saúde & 4 & 14,3 \\
\hline Falta de médico & 4 & 14,3 \\
\hline Demanda excessiva & 3 & 10,7 \\
\hline Sobrecarga de tarefas & 3 & 10,7 \\
\hline Falta de recursos financeiros para manutenção da unidade & 3 & 10,7 \\
\hline Inexistência de carro & 3 & 10,7 \\
\hline Pressão da comunidade & 2 & 7,1 \\
\hline Equipe grande - com grande número funcionários - & 1 & 3,6 \\
\hline Falta de telefone & 1 & 3,6 \\
\hline Salário inadequado para a carga de compromissos assumidos & 1 & 3,6 \\
\hline Territorialização inadeQuada & 1 & 3,6 \\
\hline EQuipe reduzida & 1 & 3,6 \\
\hline
\end{tabular}

uma complexidade e maturidade, deveria possuir trabalhadores com a função exclusiva de gerente, para Que o mesmo possa planejar melhor as ações no território, acompanhar e intervir nos indicadores, desenvolver uma articulação inter e institucional com mais efetividade, desenvolver tecnologias mais apropriadas, analisar com mais competência o processo de trabalho da equipe, compreender os processos sociais, culturais, políticos e históricos do território, supervisionar e intervir, nos diversos setores da unidade de referência da eQuipe e desenvolver uma gestão com base nas metas operacionais do sistema e no próprio Plano Municipal de Saúde.

Em pesquisa realizada por Vanderlei(5), com gestores e gerentes da ESF no estado do Maranhão, foram identificadas as seguintes dificuldades no gerenciamento: o financiamento, o perfil dos 
profissionais, a oferta de educação, os recursos materiais, a estrutura física e a oferta de medicamentos.

A segunda dificuldade mais referida pelos gerentes $(n=9)$ foi a estrutura física da unidade inadequada. Os CSF devem apresentar uma estrutura física adequada aos diversos serviços e procedimentos: vacinação, terapia de reidratação, medidas antropométricas, aerosolterapia, curativos, consultórios de enfermagem, consultório médico, consultório de saúde bucal, copa, banheiros internos e externos, triagem, recepção, esterilização, guarda de material, atividades educativas. Quando em uma unidade há uma concorrência de técnicas/procedimentos em um mesmo espaço físico, isto gera um complicador para os trabalhadores, capaz de aumentar a tensão do processo de trabalho, desmotivando e interferindo na Qualidade de vida no trabalho. O Que se espera da estrutura de uma unidade da ESF não é Que seja perfeita ou padrão, mas Que possa conformar no espaço todas as suas necessidades organizativas, assistenciais e da comunidade.

Os CSF de Sobral apresentam-se em duas situações estruturais. A primeira, uma estrutura física de excelente Qualidade, com espaços para os mais diversos serviços, com uma ambiência favorável e agradável, Que permite um acolhimento satisfatório aos sujeitos em todas as fases do processo de cuidar. Na segunda, as unidades são alocadas em residências alugadas, com péssima estrutura física, adaptada conforme as possibilidades, em Que os trabalhadores conflitam-se permanentemente por espaços. Nesse segundo tipo de estrutura, as concepções de biossegurança e de higienização dos espaços são difíceis de praticadas no dia-a-dia, devido às condições de trabalho serem limitadas pelo espaço físico exíguo e inadequado.

$\mathrm{Na}$ ESF tem sido comum a implantação de equipes em unidades de saúde adaptadas. Nos últimos tempos tem se falado muito sobre Qualidade e muitas são as ferramentas de avaliação da melhoria da Qualidade no campo da APS. Mas, como avaliarmos, ou melhor, como trabalharmos o componente da Qualidade em unidades Que não oferecem a condição estrutural mínima? Como exigir das equipes e de seus gerentes melhores indicadores e uma melhor atenção holística e de Qualidade, com vínculos precários e organização amadora do espaço?

Nesse sentido, Pereira ${ }^{(15)}$ afirma Que o papel gerencial da UBS se reveste de muitos desafios e dificuldades operacionais, durante o processo de trabalho, com o intento de mediar todas as demandas físicas estruturais e de pessoal.

Dos gerentes, seis apontaram a falta de capacitação para o gerenciamento, como mais um aspecto dificultador do trabalho. Segundo Brouwere e Balen ${ }^{(16)}$ "“....] onde a APS é de vital importância, reQuer uma boa gestão, e para o desempenho desta função tem Que distribuir em um período relativamente breve uma formação adequada".

Seis dos gerentes referem à "politicagem" existente nos territórios como um dos aspectos Que mais interferem negativamente em seu processo de trabalho, conforme apresentado na fala da gerente Maria das Dores:

[...] uma das dificuldades maiores [...] é o problema de política [...]. Porque eu não acho justo um funcionário ter Que trabalhar oito horas para poder receber seu dinheiro, e outros trabalham Quatro e recebem por oitos horas. Isso aí eu nunca achei justo.
Como também as dificuldades Que a gente tem por conta dos transportes. Lá tem uma ambulância que diz que é da associação. Só Que assim, a associação não paga o conserto, não paga o motorista, não paga gasolina, não paga nada! Assim Quando eu necessito de encaminhar uma pessoa para Sobral, às vezes uma urgência, se não for do partido não é liberado o carro. Só é liberado o carro se for do partido. Se for adversário não é liberado. Não é o gerente Que tem o controle desse carro. É a maior dificuldade que tem na área.

A prática clientelista caracteriza uma das formas de resposta do Estado brasileiro às demandas sociais, desde o início de sua constituição, no Segundo Império, aprofundando-se como processo na República Velha e adQuirindo roupagem tecnocrática na Ditadura Militar, como bem demonstra Luz ${ }^{(17)}$. A região Nordeste tem sido cenário privilegiado desta lógica política de sobrevivência eleitoral dos políticos de carreira.

Para Bobbio, Matteucci e Pasquino ${ }^{(18)}$ há um estilo de clientelismo em que os políticos de profissão oferecem como "troca da legitimação e apoio - consenso eleitoral -, toda a sorte de ajuda política Que tem ao seu alcance - cargos e empregos públicos, financiamentos, autorizações dentre outros".

A Cidadania na saúde, de acordo com Medeiros ${ }^{(19)}$ "começa na descoberta de Que as ações e serviços de saúde não são um favor ou ato de caridade, mas sim um direito constitucionalmente exigível e para cujas ações todos colaboram por intermées todos colaboram por intermas sim um direito constitucionalmente exigivel inculados ao pensamento crvolver o conjunto dos tradio de tributos denominados contribuições sociais".

A ESF, por seu contato direto com o povo, e a comunidade, com suas demandas e suas lideranças religiosas, políticas, corporativas e comunitárias, vivem intensa proximidade Que expõem sobremaneira os profissionais, deixando-os suscetíveis ao processo político local, assim favorecendo uma cultura fisiológica de troca. E como o campo da saúde é eleitoralmente sensível, gerando promessas e votos, o poder político local busca apropriar-se do dispositivo da ESF como saída para contabilizar votos. Temos visto na experiência, durante andanças em muitos municípios da zona norte do Estado do Ceará, Que os conhecidos "cabos eleitorais" aproximam-se da ESF, com o intuito de melhorar seus redutos eleitorais, chegando a interferir no processo de trabalho e na autonomia profissional e gerencial.

Na ESF deve ser estimulada a gestão participativa, como elemento do desenvolvimento da democracia e da cidadania plena. No entanto, poderá haver incompreensão ou má utilização da prática gerencial no território, em Que os posicionamentos políticos, os poderes legais, instituídos ou delegados, associado ao partidarismo político, utilizam sua força para ampliar seus horizontes eleitorais. Mesmo assim, o gerente com toda sua equipe devem aproveitar esses espaços para o exercício coletivo, com as famílias, do controle social.

No caso da ESF, como política de desenvolvimento da APS, descentralizada em territórios homogêneos, não deveria haver dúvida sobre a autonomia de seus gerentes, no Que concerne ao planejamento, à gestão de pessoal e à implantação de novas práticas, com base nas demandas de necessidades. Impõe-se pensar uma lógica de desempenho que inclua a liberdade de gerenciamento do território, com controle dos processos, embasado em indicadores 
de resultados, na perspectiva da autogestão.

Campos e Campos ${ }^{(20)}$ apontam a autonomia como um dos objetivos ou finalidades principais da política, da gestão e do trabalho em saúde, seja na área da Clínica ou no campo da Saúde Coletiva. A autonomia permite Que os sujeitos atuem em um contexto, a partir de objetivos ou leis estabelecidas de forma democrática. A autonomia caminha junto à democracia participativa e é construída historicamente, como fruto de um processo individual-social. "O sujeito autônomo é o sujeito do conhecimento e da reflexão. Reflexão sobre si mesmo e sobre o mundo. Mas autonomia depende também da capacidade do sujeito de agir sobre o mundo, de interferir sobre sua rede de dependências [...]". Na realidade, segundo os autores, a "autonomia plena não existe, nem seria bom Que houvesse, pois seria um retorno à vida selvagem, em cima das árvores". Já Cecílio ${ }^{(21)}$ afirma Que "uma pessoa só tem autonomia Quando possui o poder de controlar seu próprio trabalho e, decorrente deste controle, é Que pode ser responsável pelas ações Que desencadeia".

No Que concerne à burocracia, cinco gerentes referiram o fato como existente e negativo. A prática da burocracia, este excesso e esta disfuncionalidade administrativa, parece ser tão antiga Quanto à história do serviço público brasileiro. No setor saúde a burocracia tem sido utilizada como um meio de travar os processos, de discriminar negativamente o atendimento de interesses, de controlar e reduzir gastos, de exibir poder discricionário dos titulares.

No território da ESF, a burocracia tem sido responsável pelo não cumprimento do planejamento, por conta do veículo Que transporta a eQuipe apresentar defeito e demorar seu conserto, não permitindo o deslocamento desta equipe para as microáreas, ou mesmo da zona urbana para zona rural. A demora na distribuição de insumos, a exemplo daQueles próprios da sala de vacina ou de consultório de saúde bucal, Que interrompe ações programáticas, resultando em desperdício de carga horária de profissional e em ofensa aos direitos dos membros da comunidade.

São muitos os exemplos da lógica burocrática no território da ESF, dentre eles citamos: a demora na liberação de peфuenos reparos, reformas e ampliação do espaço físico; a auuisição de novas tecnologias; o elevado número de Sistemas de Informação em SaúdeSIS, com sua variedade de formulários e a falta de comunicação entre eles; o número excessivo de formulários que devem ser preenchidos a partir da produção ambulatorial e distribuição de insumos farmacêuticos; a postura hierárQuica da gerência e profissionais com graduação em relação aos de formação técnica; a racionalidade profissional emanada por categorias hegemônicas; e o elevado número de normas emanadas das Secretarias Estadual e Municipal da Saúde e do MS.

Weber ${ }^{(10)}$, em sua obra Ensaios de Sociologia, autor do conceito de Burocracia, apresenta como características da burocracia moderna o seguinte: "I) Rege o princípio de áreas de jurisdição fixas e oficiais, ordenadas de acordo com regulamentos, ou seja, por leis ou normas administrativas: a) As atividades regulares necessárias aos objetivos de estrutura governada burocraticamente são distribuídas de forma fixa como deveres oficiais. b) A autoridade de dar as ordens necessárias à execução desses deveres oficiais se distribui de forma estável, sendo rigorosamente delimitada pelas normas relacionadas com os meios de coerção, físicos, sacerdotais ou outros, Que possam ser colocados à disposição dos funcionários ou autoridades. c) Tomam-se medidas metódicas para a realização regular e continua desses deveres e para a execução dos direitos correspondentes, somente as pessoas Que têm Qualificações previstas por um regulamento geral são empregadas. Nos Governos públicos e legais, esses três elementos constituem a 'autoridade burocrática' [...]. II) Os princípios da hierareuia dos postos e dos níveis de autoridades significam um sistema firmemente ordenado de mando e subordinação, no Qual há uma supervisão dos postos inferiores pelos superiores. [...]. III) A administração de um cargo moderno se baseia em documentos escritos - 'os arquivos' -, preservados em sua forma original ou em esboço. [...]. IV) A administração burocrática, pelo menos toda a administração especializada - Que é caracteristicamente moderna - pressupõe habitualmente um treinamento especializado. Isto ocorre cada vez mais com o diretor moderno [...], e também com o funcionário do Estado. [...]. VI) $\mathrm{O}$ desempenho do cargo segue regras gerais, mais ou menos estáveis, mais ou menos exaustivas, e Que podem ser aprendidas. O conhecimento dessas regras representa um aprendizado técnico especial, a Que se submetem esses funcionários [...]".

No caso da ESF, fazendo uma leitura do Que afirma Alves, apesar de se buscar um modelo de gestão participativa, não fica evidente, claro, nos territórios, Que competências cada categoria profissional e, diversos outros trabalhadores de saúde devem desenvolver, Que normas e/ou rotinas gerenciais durante o processo de trabalho devem cumprir ou seguir, e Que tipo de registros devem ocorrer. As atribuições distribuídas nem sempre são compreendidas como um dever oficial do nível de gestão sanitária. A própria burocracia parece ser truncada, sem exibir QualQuer das características Que a defenderiam como forma de gestão.

As equipes de saúde, Que atuam no território hospitalar, apresentam uma maior facilidade de compreender a burocraciapositiva estabelecida por seus diferentes níveis e entes da gestão - conselho gestor, administrador, gerentes e diretores das diversas corporações -, situação esta, Que foi desconstruída durante o desenvolvimento da ESF, talvez por sua lógica organizativa se basear na orientação comunitária, e os sujeitos Que nela vivem não aceitarem a burocracia-positiva como uma prática na gestão da atenção à saúde.

\section{CONCLUSÕES}

Nas falas dos gerentes acerca do processo Que os levou ao cargo, apresentadas nas categorias, fica claro Que sua ascensão ao cargo deu-se de maneira administrativamente artesanal, com base em sentimentos de alguns, em "achismos", em constância da presença, em maior disponibilidade da força de trabalho, mas, sobretudo, pelo o olhar da Coordenação Municipal de APS, sem a utilização de critérios técnicos ou políticos, acerca do processo de trabalho e das competências individuais do profissional.

O território da ESF, um território sanitário infra-municipal, constitui-se em arena onde ocorrem e disputam micro-poderes das ordens social, política, econômica, cultural e sanitária, exigindo gerência com liderança democrática, flexibilidade política, competência sobre o cuidado na APS e na gestão do SUS. Sua seleção deve obedecer a sólidos critérios, tendo por base um perfil estabelecido a partir do proposto pelas macropolíticas sanitárias 
municipais e pelas demandas administrativas

No Que concerne ao processo Que levou o enfermeiro ao cargo de gerente, deveu-se as características pessoas como liderança e organização durante o processo de trabalho; além de ser uma função enfermeiro-centrado e exercida por indicação de terceiros à equipe.

As principais facilidades no seu processo de trabalho durante o gerenciamento do território relatado pelos gerentes são: bom relacionamento com a equipe, 39,3\%; a organização do serviço de saúde [...], 2 1,4\%; e equipe compromissada com o trabalho, 17,9\%. Em contraponto, as principais dificuldades são: conciliar atividade de enfermagem e gerenciamento, 35,7\%; estrutura física da unidade, 32, 1\%; falta de capacitação para o gerenciamento, 21 ,4\%; e a politicagem por parte dos cabos eleitorais, 21 , 4\%.

Estabelecer critérios de seleção dos gerentes Que desconsiderem a conveniência do mesmo está no território, mas sim com base em critérios técnicos Que levem em consideração competências técnicas gerenciais, sociais e humanas, além do espírito de liderança.

\section{CONSIDERAÇÕES FINAIS}

Assim sugerimos Que:

Os gerentes durante o desenvolvimento de seu processo de trabalho, poderão:

- Disponibilizar tempo para a supervisão e organização do Centro de Saúde da Família.

- Reduzir o tempo com demandas emergentes e burocracia, deixando tempo para a organização do Centro de Saúde da Família.

- Delegar aos enfermeiros do território a responsabilidade técnica de supervisão, organização e controle de serviços como sala de vacina, de aerosolterapia, TRO, de curativos e retiradas de suturas, de procedimentos, de material e esterilização, com o intuito de reduzir a burocratização e as atribuições gerenciais, possibilitando os gerentes atuar em processos gerenciais mais complexos.

A SMSAS poderá:

- Estabelecer as atribuições dos gerentes.

\section{REFERÊNCIAS}

1. Goya N. O SUS Que funciona nos municípios do Ceará. Fortaleza (CE): Fundo das Nações Unidas para a Infância/ Associação dos Município do Estado do Ceará; 1996.

2. Ministério da Saúde (BR). Departamento de Atenção Básica. Guia prático do programa saúde da família. Brasília (DF): Ministério da Saúde; 2001.

3. Ministério da Saúde (BR). Secretaria de Assistência à Saúde. Saúde da Família: uma estratégia para a reorientação do modelo assistencial. Brasília (DF): Ministério da Saúde; 1997.

4. Antunes MIM, Egry EY. O Programa Saúde da Família e a reconstrução da atenção básica no SUS: a contribuição da enfermagem brasileira. Rev Bras Enferm 2001; 54(I): 98 107.

5. Vanderlei MIG. O gerenciamento na Estratégia Saúde da Família: o processo de trabalho dos gestores e dos gerentes municipais de saúde em municípios do Estado do Maranhão [tese]. Ribeirão Preto (SP): Escola de Enfermagem de Ribeirão Preto, Universidade de São Paulo; 2005.
- Avaliar o perfil dos gerentes durante a nomeação, e confrontálo com o perfil Que o sistema exige.

- Prover o gerente de mais autonomia. É evidente a autonomia responsável na prática dos gerentes, para uma tomada de decisões no gerenciamento do território é de fundamental importância. Sabendo Que a autonomia é necessária para a priorização das ações a serem desenvolvidas pela equipe durante o cuidado aos sujeitos, famílias e comunidades.

- Disponibilizar uma boa equipe e de todos os recursos necessários para o alcance de metas e da excelência gerencial, para o exercício de uma gerência competente.

- Deixar claro para as equipes, Quais são as macropolíticas sanitárias do município e os gerentes, gerenciarem o alcance das mesmas no território.

- Avaliar o desempenho dos gerentes, pois nos territórios existem gerentes extremamente competentes e outros descontextualizados para o exercício do cargo.

- Estabelecer uma nova política gerencial de apoio aos gerentes, no Que concerne ao provimento de insumos, equipamentos e manutenção, com a redução de níveis hierárquicos e de burocracia.

- Estabelecer um sistema de crédito financeiro, com base em suprimento de fundos, para os territórios, com o intuito de estar provendo peQuenos serviços de manutenção e aQuisição de insumos de pequeno vulto, de maneira rápida e prática, contribuindo com a redução da burocratização e o entrave de determinadas fases do processo de trabalho da equipe e da gestão sanitária municipal, principalmente, nos períodos de licitação e compra.

- Dar exclusividade de trabalho gerencial ao gerente, nos territórios em Que os indicadores epidemiológico-sociais sejam críticos, com densa lista de necessidades sócio-sanitárias e elevada população adscrita, o gerente de território atuar exclusivamente nas ações gerenciais do território.

- Estabelecer critérios de seleção dos gerentes Que desconsiderem a conveniência do mesmo está no território, mas sim com base em critérios técnicos Que levem em consideração competências técnicas gerenciais, sociais e humanas, além do espírito de liderança.

6. Campos GWS. A saúde pública e a defesa da vida. $2^{\text {a }}$ ed. São Paulo (SP): HUCITEC; 1994.

7. Campos GWS. Considerações sobre o processo de administração e gerência de serviços de saúde. In: Campos GWS, Merhy EE, Nunes ED. Planejamento sem normas. $2^{\text {a }}$ ed. São Paulo (SP): HUCITEC; 1994. p. 9-31.

8. Minayo MCS. Ciência, técnica e arte: o desafio da pesquisa social. In: Minayo MCS, organizadora. Pesquisa social: teoria, método e criatividade. 22ª ed. Petrópolis (RI): Vozes; 2003. p. 9-29.

9. Shinyashiki R. Donos do futuro. São Paulo (SP): Editora Infinito; 2000.

10. Weber M. Ensaios de sociologia. $5^{\mathrm{a}}$ ed. Rio de Janeiro (RJ): LTC; 2002.

11. Alves LAAR. O perfil gerencial do Enfermeiro para atuar na atenção primária em saúde. In: Santos AS, Miranda SMRC, organizadores. A enfermagem na gestão em atenção primária à saúde. Barueri (SP): Manole; 2007. p. I I l-22. 
Processo de ascenção ao cargo e as facilidades e dificuldades no gerenciamento do território na Estratégia Saúde da Família

12. Cunha ICKO, Ximenes Neto FRG. Competências gerenciais de enfermeiras: um novo velho desafio? Texto Contexto Enferm 2006; 15(3): 479-82.

13. Santos AS. Gestão em atenção primária à saúde e enfermagem: reflexões e conceitos importante. In: Santos AS, Miranda SMRC, organizadores. A enfermagem na gestão em atenção primária à saúde. Barueri (SP): Manole; 2007. p. 1-40.

14. Chiavenato I. Gestão de pessoas: o novo papel dos recursos humanos nas organizações. Rio de Janeiro (RI): Campus; 1999.

15. Pereira SA. Modos de gerenciar cuidado e serviço no Programa Saúde da Família em Belo Horizonte [dissertação]. Belo Horizonte (MG): Escola de Enfermagem, Universidade Federal de Minas Gerais; 2005.

16. Brouwere V, Balen HV. Formación pratica em matéria de gestión sanitária de distrito. Foro Mundial de la Salud 1996; 17(3): 388-90.
17. Luz MT. Medicina e ordem médica no Brasil. Rio de Janeiro (RI): Edições Graal; 1982.

18. Bobbio N, Matteucci N, Pasquino G. Dicionário de política. $6^{a}$ ed. Brasília (DF): Universidade de Brasília; 2003.

19. Medeiros HI. Ministério Público: reforço do poder da cidadania e do controle social. In: Brasil. Conselho Nacional de Saúde-CNS. In: Cadernos da I I ${ }^{\text {a }}$ Conferência Nacional de Saúde. 15-19 dez 2000, Brasília (DF), Brasil. Brasília (DF): Conselho Nacional de Saúde; 2000. p. 101-15.

20. Campos RTO, Campos GWS. Co-construção de autonomia: o sujeito em Questão. In: Campos GWS. Tratado de Saúde Coletiva. São Paulo (SP): HUCITEC; 2007. p. 669-88.

21. Cecílio LCO. Autonomia versus controle dos trabalhadores: a gestão do poder no hospital. Ciência \& Saúde Coletiva 1999; $4(2): 315-29$. 